\title{
REPRESENTACIONES DEL CUERPO, SEXO Y GÉNERO ENTRE LOS AYMARA DEL NORTE DE CHILE
}

\author{
REPRESENTATIONS OF THE BODY, SEX AND GENDER IN AYMARA \\ COMMUNITIES OF NORTHERN CHILE
}

\author{
Ana María Carrasco G. ${ }^{1}$ y Vivian Gavilán Vega ${ }^{2}$
}

\begin{abstract}
El propósito central de este trabajo es exponer resultados preliminares de un estudio sobre las representaciones sociales que construyen los aymara del norte chileno respecto del cuerpo, la sexualidad y la reproducción. Se trata de alcanzar una aproximación a las categorías de las diferenciaciones sexuales que permiten a los actores sentar las bases para establecer las relaciones de género. Se indaga en dos ámbitos de la vida social aymara, por un lado en las prácticas religiosas y, por el otro, en las narrativas acerca del cuerpo, el sexo y la sexualidad. Consideradas dos formas de entrada para rastrear las asociaciones simbólicas y contenidos significativos que pudieran permitir la comprensión de las diferencias sexuales; como asimismo, abrir la mirada a cómo las representaciones del cuerpo, sexo y género se relacionan con las identidades étnicas y de género de este grupo social.

Palabras claves: aymara; representaciones del cuerpo, sexo y género; sexualidad; diferencias sexuales; identidad étnica y de género.

The main purpose of this paper is to present the preliminary results of a study of the social representations created by the Aymara of Northern Chile with respect to the body, sexuality and reproduction. This article is an approach to identify the categories of sexual differentiation that allow actors to lay the foundation for gender relations. We inquire into two spheres of Aymara social life: religious practices and narratives about the body, gender and sexuality. We consider two approaches to trace symbolic associations and meaningful content which could allow an understanding of sexual differences, and bring an awareness to how the representations of the body, sex and gender are related to the ethnic and gender identities of this social group.
\end{abstract}

Key words: Aymara; body, sex, and gender representations; sexuality; sexual differences; ethnic and gender identities.

Los estudios acerca de las relaciones de género en América Latina han estado orientados a comprender las relaciones sociales entre mujeres y hombres en la estructura social y particularmente a entender el hecho generalizado de la dominación masculina. La universalización de este problema olvida, a veces, las formas distintas que ha asumido ésta en la historia y también de acuerdo con los contextos culturales diferenciados. Este hecho es particularmente relevante en países como el nuestro, dada la gran heterogeneidad de clase y étnica en la que convivimos. Por otra parte, el énfasis puesto en las relaciones de poder en ocasiones olvida que las construcciones sociales del género se explican, también, por los contenidos culturales otorgados al cuerpo, sexo y sexualidad de la humanidad, los cuales forman parte del comportamiento de los sujetos sociales.
Si bien pensamos que es el enfoque combinado de lo social y lo simbólico el que nos podría conducir a una mejor aproximación de las relaciones de género en todos los grupos sociales y étnicos, en este artículo nos proponemos presentar información sobre las representaciones del cuerpo, sexo y reproducción humana entre los aymara del norte chileno. El interés inicial de investigación fue estudiar la religiosidad andina desde una perspectiva de género, a fin de conocer las ideas que sustenta esta población en relación a lo femenino y lo masculino y sus relaciones $^{1}$. Durante el proceso de trabajo tomamos en cuenta que un aspecto fundamental era detenerse en las concepciones acerca de la reproducción para entender las complejas relaciones entre las divinidades y las prácticas rituales. Se trataba de una cuestión recíproca; para entender las relaciones de género era importante conocer los aspectos simbólicos

1 Departamento de Antropología, Universidad de Tarapacá, Arica, Chile. amcarrasco@uta.cl

2 Centro de Investigaciones del Hombre en el Desierto (CIHDE), Iquique, Chile. viviangav@yahoo.com 
y la religiosidad podía ser un espacio interesante de estudio; pero, al mismo tiempo, indagar en la religiosidad nos llevó a conocer cómo los aymara, sujetos de nuestro estudio, concebían la naturaleza del cuerpo humano y de su reproducción, aspectos centrales para comprender los distintos rituales y el discurso religioso.

En esta línea, el propósito es alcanzar una mejor aproximación a las categorías de las diferenciaciones sexuales que utilizan los aymara del norte de Chile, como una base que nos ayude a comprender las relaciones sociales de género.

Los aymara son un grupo étnico de los Andes meridionales, cuya presencia comprende tres países: Bolivia, sur del Perú y norte de Chile. En este último país, según datos del Censo de Población y Vivienda 2002, alcanzan una población de 48.501 personas (INE 2003), presentes principalmente en la zona norte y distribuidas en las ciudades de la costa y en comunidades rurales de las zonas de valle y altiplano, en la frontera de Perú y Bolivia. El trabajo de investigación se basó en historias de vida y entrevistas a hombres y mujeres aymara, de diferentes opciones religiosas, distintas edades y residentes tanto en la zona rural como urbana del norte de Chile ${ }^{2}$. Además, nuestra participación en los rituales más importantes de las comunidades a través de más de dos décadas de trabajo en la zona de estudio fue, igualmente, de gran utilidad ${ }^{3}$. De igual forma, la agregación de antecedentes realizada a partir de varios aportes de otros investigadores acerca de 'la religiosidad' andina constituyó para la investigación y constituye para este artículo una pieza central; aun cuando debemos mencionar que a pesar de la gran cantidad de textos sobre religiosidad son pocos y recientes los que sintetizan o debaten resultados (Spedding 2004). Si bien esto presenta la desventaja de la dispersión, ofrece la ventaja de la diversidad y posibles puntos de articulación, diferencias y semejanzas entre diversas opciones teórico-metodológicas y en contextos socioculturales e históricos distintos, con los cuales podemos contrastar nuestra información acopiada.

En cuanto a la estructura del texto, la primera parte intenta definir la aproximación teórica y la metodología con la cual abordamos el problema. Definimos dos ámbitos interrelacionados de la vida social aymara para identificar las representaciones del género, del cuerpo y de la reproducción. Por un lado, las prácticas religiosas y, por el otro, narrativas acerca del cuerpo, el sexo y la sexualidad.
Dos formas de entrada para rastrear las asociaciones simbólicas y contenidos significativos que nos pudieran permitir la comprensión de cómo se manejan las diferencias sexuales. Posteriormente nos referimos a las concepciones acerca del sexo, sexualidad y reproducción en las comunidades andinas en general; luego vemos las representaciones de lo femenino y lo masculino y sus relaciones en la organización social y espacial de la comunidad; finalmente, intentamos establecer una síntesis de las categorías de la diferenciación sexual y de género a partir de los antecedentes descritos, concluyendo algunas reflexiones.

\section{El Sexo, la Sexualidad y el Género}

La relación entre sexo, sexualidad y género es compleja, debido a que los conceptos de género cuestionan el carácter determinante del sexo biológico como explicativo de las características diferenciales atribuidas a los distintos sujetos. En la teoría sociológica, la preocupación ha estado centrada en cómo delimitar lo biológico de lo socio-cultural, haciéndose hincapié en el peligro que puede surgir al restringir el sexo a la biología ya que se pierde de vista cómo cada cultura piensa esa "marca" del cuerpo; como asimismo el significado simbólico diferencial que le otorga y que permite la construcción de la asimetría, supuestamente natural, entre hombres y mujeres. Una conclusión obvia de este enfoque es que habría que pensar esta relación en términos de constructos sociales. La hipótesis central será entonces que el sexo biológico siempre ha sido objeto de elaboraciones sociales independientemente de los descubrimientos propios de la biología o de la medicina. En esta línea, se han utilizado como argumentos los resultados de estudios históricos para Occidente que han señalado que es a finales del siglo XIX cuando se asienta la idea de la existencia de dos esencias biológicas diferentes. A partir de aquí, no se trataría de descubrimientos biológicos, sino más bien de fabricar representaciones que tengan utilidad política. De este modo, lo que sabemos sobre el sexo y la sexualidad y el cómo la vivimos ${ }^{4}$ son productos del desarrollo de una producción de sentido en la que intervienen los avatares de la política, la economía, la religión y la ciencia. El sexo y la sexualidad no siempre han sido pensados (ni vividos) de la misma manera.

Pero, como han planteado varias autoras, el debate continúa. En palabras de Lamas (2002), el problema es 
que la visión constructivista de la naturaleza humana ha eludido tanto lo biológico como lo psíquico. Esta autora sugiere que el énfasis puesto en "la cosificada" perspectiva de género ha promovido el voluntarismo en relación con la diferencia sexual, sin considerar ni los datos biomédicos ni los conceptos psicoanalíticos de pulsión, deseo e inconsciente. Su propuesta es que si aceptamos la importancia que adquiere la "fractura" síquica que introduce en el inconsciente la configuración diferencial del cuerpo habría que realizar un movimiento en dos direcciones:

Por un lado, comprender que los comportamientos sociales masculinos y femeninos no dependen en forma esencial de los hechos biológicos; y, por el otro, explicar cómo los procesos síquicos toman forma en la actividad de la sociedad. Esto nos obliga a otorgar el peso debido a la compleja estructura de la especie humana: el cuerpo en su condición de carne, mente e inconsciente (Lamas 2002:16).

En el contexto de este debate, Moore (1994) señalaba las dificultades para elaborar el género como concepto. Sostuvo que éste fue definido como una construcción social bajo la idea que no está determinado por la biología, no siendo reconocido el hecho que tanto la cultura como la biología han sido conceptos históricos y culturalmente variables al igual que las relaciones entre ellos. Señaló que a partir de Foucault surgieron dos tendencias:

Por un lado, la distinción entre sexo-género en el discurso antropológico le resta valor a la biología. Por el otro, y seguido de lo anterior, no es posible asumir que necesariamente el sexo biológico binario provee en todas partes la base universal para las categorías masculino y femenino. Si el género es culturalmente variable, lo son también las categorías de las diferencias sexuales (Moore 1994:13).

En los años siguientes Moore (1999) reafirma la confusión entre las conexiones entre sexo y género. Planteó, entonces que el aspecto problemático de la discusión redundó en una abstracción de los cuerpos sexuados bajo la forma de diferenciación binaria. Una de las opciones posibles de salir, a inicios de la década de 1990, fue situando la atención en la relación entre sexo y género, esto es, entre cuerpos sexuados y representaciones culturales, de este modo el sexo volvió a ser comprendido como el producto de un discurso regulatorio del género en el que el aspecto físico de los cuerpos está diferencialmente marcado y cargado de significados. En esta última perspectiva, propone que Butler (1990) argumentó la inestabilidad de la categoría analítica sexo-género. El género fue visto como eje del proceso de identidad al estructurar la subjetividad. Fue pensada no como una estructura fija de relaciones (género performativo). Así, los géneros serían un proceso, se hacen, no sólo se resignifican sino que no tienen un origen ni un fin. Moore propone, de este modo, que Buttler entendió el sexo como el efecto de los discursos regulatorios del género asumiendo que tales discursos se imponen a una heterosexualidad compulsiva, cayendo en una visión esencialista de la agencia y la subjetividad (Moore 1999:155).

En las últimas décadas y rescatando una obra clásica en esta materia, tenemos que los resultados de las investigaciones desde la ciencia biológica nos indican que existirían al menos tres tipos distintos de sexo: el sexo morfológico (determinado por los genitales externos); el sexo genético (dado por las manifestaciones fenotípicas del sexo determinado por influencias endocrinas), y el sexo cromosómico (que corresponde a la presencia del genotipo XX y XY en las células somáticas) (Money 1986). La institucionalidad científica se ha apropiado de la distinción entre sexo y género, definiendo sexo como la clasificación de los entes vivos en machos y hembras, de acuerdo con sus órganos reproductivos y las funciones asignadas por su determinación cromosómica. Género, en tanto, tomando la definición de Lamas, corresponde básicamente, a la autorrepresentación de las personas a partir de su presentación individual (Lamas 2002:17).

Visto así, los datos biomédicos nos permiten afirmar que el carácter binario y excluyente del sexo entre los seres humanos varía según el nivel de análisis en que nos situemos; se descubre que el par hombre/mujer tiende a ser un continuo entre dos polaridades, donde el sitio exacto del corte no es tan claro. Pero esta maleabilidad de lo biológico tiene límites; llegado un momento los seres son definidos, sin duda, sexualmente, desde un punto de vista biológico. Sobre esta definición sexual, la interacción social a que sea expuesto el nuevo ser irá determinando la construcción de su identidad psíquica y social, el proceso de adquisición de su múltiple identidad, rol y orientaciones sexuales; es decir, la definición de su sexualidad: 
El conjunto de las maneras muy diversas en que las personas se relacionan como seres sexuados con otros seres sexuados, en intercambios que, como todo lo humano, son acciones y prácticas cargadas de sentido (De Barbieri 1992:117).

$\mathrm{Al}$ conceptuar la sexualidad como una elaboración síquico-cultural de los placeres en los intercambios corporales, ciertos temas como la orientación sexual han cobrado una dimensión diferente. Cualesquiera que sean los orígenes de dicha orientación, lo que cuenta son los significados que las personas les atribuyen y los efectos que esa valoración tienen sobre la manera en que organizan su vida sexual (Lamas 2002).

Desde la perspectiva de los estudios sociales, el sexo biológico puede o no corresponder al asignado, pero siempre hay una rotulación. Siempre hay sexos distintos y se pertenecerá fundamentalmente a uno de ellos. Esta pertenencia al sexo masculino o femenino será la base de la identidad de género, ya que el medio social tratará a ese sujeto como perteneciente al género que le fue asignado, entregándole todo el bagaje cultural en torno a los significados del ser hombre o mujer y el tipo de relaciones que podrá establecer con los otros u otras (Lamas, 2002:24). Asimismo, la sexualidad, si bien es orientada por las atribuciones culturales a los sexos-géneros, será una construcción social y cultural en torno a la cual los sujetos sociales van definiendo durante su vida. De acuerdo a Godelier:

El entramado de la simbolización se hace a partir de lo anatómico y de lo reproductivo; todos los aspectos (económicos, sociales y políticos) de la dominación masculina se explican por el diferente lugar que ocupa cada sexo en el proceso de la reproducción sexual (Godelier 1986:45).

En el contexto de este debate, partimos del supuesto que el concepto de género como herramienta analítica aporta una base teórica y conceptual para conocer las asociaciones simbólicas de las diferencias sexuales. Si entendemos la cultura como un entramado de símbolos y al género como una parte de éste, asumimos que podemos acceder a los significados que mujeres y hombres aymara concretos otorgan a estas diferencias. Asimismo, si entendemos la cultura como resultado y como mediación se entenderá que estos significados son constructos históricos y que los sujetos perciben la vida a través de lentes que les proporciona su cultura (Lamas 2002). En palabras de Harris (1980), el establecimiento de vínculos simbólicos entre el género y otros aspectos de la vida cultural son observables en un gran número de sociedades. De esta manera es posible estudiar los símbolos construidos en torno al género como elementos que arrojan luz respecto de otras esferas de la vida social; asimismo es posible encontrar nociones relacionadas con los conceptos y las ideas acerca de lo femenino y lo masculino en diferentes áreas de la vida de un pueblo. El género se encuentra entonces arraigado en ámbitos tan diversos como la conceptualización del espacio, las ideas acerca de la naturaleza, la organización de la estructura política, o las prácticas creencias y deidades de la religión.

$\mathrm{Al}$ enfrentarnos al estudio de las categorías de las diferencias sexuales entre los aymara del norte chileno, utilizamos el concepto de género como una construcción simbólica que nos permita reconstruir los significados asignados a estas categorías en la población estudiada. El planteamiento de este o de otros objetos de investigación lleva consigo la complejidad de irrumpir en sistemas articulados de ideas. El abordaje supone fragmentar la realidad de una manera arbitraria, pero justificable. En este sentido, tenemos presente que a pesar de los procedimientos de contrastación entre nuestros conceptos y los conceptos aymara, existirá nuestra propia visión del problema, la que nos remite al momento histórico que vivimos y a nuestras ideas acerca del cuerpo, del sexo, de la sexualidad y de las relaciones sociales entre mujeres y hombres.

\section{El Sexo, la Sexualidad y la Reproducción en las Representaciones Andinas}

Sólo en los últimos años se han desarrollado estudios específicos acerca de las ideas sobre el cuerpo, el sexo, la sexualidad y el género entre la población indígena en los Andes. Este tema, aparecido persistentemente en los estudios sobre "religiosidad" desde la década de 1970 (Albó 1992; Bastien 1996; Cadorette 1977; Dalles 1971; Grebe 1981; Harris 1980; Martínez 1990, 1996; Montes 1986; Platt 1980, 2003; van Kessel 1992a, 1993), no aborda la problemática desde una visión de género, pero contribuye como punto de partida para esta nueva mirada. 
Los resultados de investigación acerca de la cosmovisión andina y sobre las prácticas e ideas religiosas presentan la ventaja de ofrecer una variada y rica información respecto de las concepciones culturales del cuerpo, sexo y género que nos permiten reconstruir sus representaciones. Sin embargo, entre las desventajas podemos mencionar un camino indirecto de abordaje, lo que deja vacíos y preguntas clave para nuestra comprensión de las diferencias entre mujeres y hombres y entre lo femenino y lo masculino. Una breve evaluación de la literatura sugiere que a pesar de las diferencias en las interpretaciones tanto de los autores como de los actores se observan semejanzas en las formas de clasificación y en la asociación simbólica asignadas a lo femenino, a lo masculino y a sus relaciones.

Una primera hipótesis, planteada por Platt (2003), puede sernos útil para entrar desde el tema que nos interesa en este debate. En un estudio reciente sobre las ideas acerca de cómo conciben la reproducción humana, sugiere que la diferencia de género es presentada como esencial; esto es, afincada en las formas de concebir la naturaleza del cuerpo humano femenino y masculino. En su estudio sobre los Macha, Bolivia, propone que la sangre menstrual es una de las principales partes de la contribución de la mujer a la sustancia fetal y se dice que el feto es como una planta y como tal necesita humedad. El semen del hombre es una forma complementaria de la sangre en la concepción. Para los indígenas en esta comunidad existirían dos tipos de sangre: roja y blanca y los hombres tendrían también un útero, en el cual se sitúa su semilla. Así, la concepción de un nuevo ser humano es posible por la combinación de ambos tipos de sangre.

De acuerdo con este autor, el ciclo menstrual de las mujeres estaría asociado con el ciclo lunar y sería el período de la luna nueva y llena el que se considera de extrema fertilidad. Durante este tiempo se piensa que la luna tiene relaciones sexuales con el sol. Identifica tres formas metafóricas para comprender la concepción humana: ordeñar la leche y la preparación del queso, el proceso textil y la fundición de los metales. La primera de ellas sitúa al hombre y a la mujer como activos sexualmente y portadores de sustancias complementarias. El sexo femenino "ordeña" al pene hasta instalar la semilla en la matriz de la mujer y producir el feto. La segunda refiere a la vagina como tejido que envuelve al pene y a la sangre coagulada (fecundada) por el semen, como el torcido de los hilos, lo que forma una bola de lana que sujeta el feto a la matriz (cordón umbilical). Las tres metáforas aluden a la concepción como el momento en que la sangre roja y menstrual de la mujer se coagula por efecto del semen, la sangre blanca del hombre (como se funden los metales). Pero el coagulado, envoltura, congelado o torcido de la sangre blanca y roja puede sólo establecer un material viable para una nueva persona si existe un conjunto de condiciones por la introducción de una chispa vital. La vida debe ser impulsada si el inicio de la coagulación germina. Esta vitalidad estaría dada por una fuerza sobrenatural asociada a las divinidades de la Tierra. La capacidad de una mujer para concebir está asociada con su piedra fértil local o $K$ 'amiri. Sería a través de ésta que la energía vital entra en la matriz de la mujer, conjunta la sangre de ambos padres produciendo, dentro, la coagulación. Vida, desde esta perspectiva, sería nacer del fondo de la tierra desde los "demonios" femenino y masculino, del deseo y poder genésico. La asociación de estos demonios con la regeneración y crecimiento se muestra también en los rituales a los aviadores (Supay), nombre dado por los cristianos al alma de los ancestros muertos. Así, el autor infiere que la chispa de la vida de las nuevas formas de fetos es un alma ancestral transmitida como emanación petrificada de un K'amiri y entonces reencarna en una nueva vida que formó la matriz como resultado del cruzamiento de la coagulación producto de ambas sustancias (Platt 2003).

La idea de los aportes diferenciados de los sexos a la concepción es señalada también por otros autores. A. Ortiz para los Chanka de Moya, sur del Perú, postula que la madre da el cuerpo, el padre la vida. Ella pone la materia y su forma, el padre el semen que es vida pura y despierta lo dormido (Ortiz 1982). Una interpretación parecida encontramos en las comunidades aymara, estudiadas, específicamente del área altiplánica (Isluga y Cariquima). Las mujeres dicen que al término del período menstrual es el momento más fértil de la mujer: "cuando uno se abre, cuando menstruación, entonces antes que se cierre eso, cuando tiene relaciones, ahí queda embarazada". La forma de preparación del queso es también aquí utilizada:

Cuando estamos con hombre ahí se cría la guagua, en la mensual, ahí cae la guagua. Cuando perdiendo tu mensual al tercer o cuarto día ahí vas a tener. Según gente también es. Los hombres y las mujeres hay 
que tener, el hombre agarra sueño no más. En ese agarra, cuando nosotros estamos echando cobaja a la leche pa' hacer queso, asimismo agarra la guagua, asimismo pesca, como dos semanas, un mes, así está como bolita en un rinconcito, clarito está. Cuando toca ¡iyau; dice. Otros días sin mensual no puede tener (Carrasco 2001:6)

En la comunidad Macha, Bolivia, el feto femenino de tres meses emerge en la coagulación de la sangre que no ha sido "solidificada", mientras que el feto masculino del mismo tiempo de gestación está ya formado. Las mujeres dicen que un feto de sexo masculino se mueve aquí y allá como un pequeño pescado mientras que una mujer se mueve más suavemente, como una nube separándose o como una ola en un lago. El tiempo de gestación puede ser medido por las nuevas lunas. Pero hay discrepancia sobre el número de meses del embarazo. Se piensa que las niñas necesitan menos tiempo para madurar que los niños, quienes deben coagular más músculos y sustancias en los huesos. De aquí que las niñas pueden nacer a los ocho meses y los niños a los nueve o casi diez meses. En este sentido, el proceso de formación del feto de sexo femenino es más tardío que el de los hombres, pero el proceso de gestación total es más largo en los hombres que en las mujeres (Platt 2003).

En un trabajo sobre los Kallawayas, Bolivia, Bastien (1996) propone que el origen del sexo del bebé se decide por fuentes humanas: el sexo contiene su embrión que se transmite directamente -en el caso de las hembras- de madre a hija; en el caso del linaje masculino, éste es trasmitido indirectamente a través de la esposa. Creen que si el hombre alcanza el clímax antes de la mujer entonces él le inyecta su embrión masculino y ella concibe un muchacho. Pero si la mujer llega al clímax antes que el hombre entonces ella gana y concibe una niña. Entre los aymara del norte de Chile, la definición del sexo está determinada también por el énfasis de las partes en el momento del coito, pero no se hace referencia directa al orgasmo, sino que se dice que nacen de sexo masculino porque es el hombre el que está más cargado, está más fuerte; y cuando son de sexo femenino es cuando la mujer está más fuerte.

Arnold (1997) propone también que lo que permite la fecundación es la mezcla del semen con un nudo de sangre menstrual coagulada durante los días de la luna nueva, cuando ya ha pasado el período menstrual. Sugiere que en estas nociones acerca de la reproducción persiste una ambigüedad respecto a las relaciones de afinidad y las de incesto, puesto que la guagua concebida en tal momento no es considerada como fruto de relaciones maritales normales. Se le considera criatura natural wajcha y se concede prioridad a su ancestro materno antes que al paterno. Propone que el principio materno es lo que estructura la manera en que se perciben el significado de las semillas de alimentos, el ciclaje de los muertos como sustancia ancestral y el ciclaje del abono fertilizante y que en torno a este transforma las categorías de afinidad y parentesco.

Entre los aymara, las mujeres dicen que son posibles otras formas excepcionales de embarazo, producidas por seres sobrenaturales que habitan en los campos; hecho que ocurre comúnmente cuando estas se quedan dormidas en los cerros. En estos casos los fetos son señalados como animales (lagartos o sapos). Esto se relaciona también con la "braveza" sexual de las deidades tectónicas. Los hombres también pueden ser violados por estos, particularmente por aquellos lugares considerados peligrosos, los que normalmente se denominan waynas o cerros jóvenes (Carrasco 1998).

A partir de un estudio de los mitos y leyendas del siglo XVI y de resultados de investigación etnográfica de una comunidad quechua del Perú, Isbell (1976) sugiere que las construcciones de género se relacionan con fuerzas extraordinarias que otorgarían tanto las especificidades sexuales así como sus relaciones. Plantea de este modo que el deseo, el sexo y la reproducción, como categorías, estarían separadas en los Andes y manejadas por fuerzas distintas. Al mismo tiempo el deseo femenino es siempre el estado "ontológicamente priorem", por ejemplo a los actos sexuales o a la creación del mundo. Por eso Isbell siempre evoca a Pachamama como el último punto de referencia para la categoría no marcada de la totalidad que abarca todo (Isbell 1976).

\section{Representaciones de lo Femenino y lo Masculino y sus Relaciones en la Organización Social y Espacial de la Comunidad}

Bastien (1996) es uno de los autores que ha abordado la relación que los aymara contemporáneos establecen entre el cuerpo humano y la organización del espacio geográfico y social. En su 
estudio sobre los Kallawaya, grupo aymara de la zona medio-oeste de Bolivia, describe cómo estos pobladores de la montaña nombran a sus lugares según la anatomía del cuerpo humano. La montaña es como un organismo, un cuerpo, las partes están unidas orgánicamente (cabeza, entrañas-corazón y las piernas). Estas partes representan a la vez los tres ayllus exogámicos residentes. Propone que el cuerpo en esta etnia es entendido como todas aquellas partes que forman un mismo interior, incluyendo el yo interior; no separando la mente del cuerpo. La parte más importante es el corazón que bombea la sangre a través del cuerpo. El corazón es el pensamiento, las intenciones y las emociones. La sangre y la grasa dan poder al cuerpo y se produce en las entrañas. Estas incluyen el hígado, riñones, estómago e intestinos. La sangre es el principio de la vida y viene del corazón; la grasa el principio de la energía y viene de las entrañas.

El cuerpo humano también se encuentra en la simbolización de los tejidos de Isluga, comunidad del altiplano chileno. Cereceda (1978) sugiere que las telas se organizan espacialmente de manera simétrica en dos mitades, nombradas como cuerpos con un centro que recibe el nombre de corazón, asociación que simbolizaría a la vez la organización social dual de la comunidad. Arajj Saya y Manqha Saya, concebidas como masculina y femenina cuyo centro remitiría al pueblo central o Marka (Cereceda 1978). La organización social y espacial pensada en términos de género simbólicamente se constata en la mayor parte de la literatura. Cada una de las mitades contiene implícitamente referencias sexuales y en relación asimétrica (mayor o menor prestigio y poder). Platt (1980) y Montes (1986) señalan la percepción de la naturaleza y de la cultura en términos de opuestos simbólicamente sexuados. Ambas se concebirían como una ampliación a mayor escala del modelo provisto por la pareja humana, la cual estaría constituida por dos individuos distintos y diametralmente opuestos en su polaridad sexual y en sus atributos. Esta oposición se resolvería a través de la cópula, comunión entre macho y hembra. Así, las parcialidades, concebidas simbólicamente en términos de género, se unen en un acto sexual también simbólico: el Tinku, un combate ritual que periódicamente enfrenta la mitad 'masculina' del ayllu con la 'femenina' (Montes 1986:128-130; Platt 1980:160). En este mismo sentido y a partir de resultados de investigación en Isluga, altiplano chileno, Grebe (1981), afirma que la diferenciación sexual sería un principio de la cosmovisión aymara, lo cual expresaría el interés de los pueblos andinos por la fertilidad y reproductividad.

Entre los aymara del norte de Chile, la fiesta de los carnavales o "floreo de la gente" es por definición el espacio de reproducción social de la comunidad. En las ceremonias que ocurren durante tres días de fiesta surge la organización espacial y social de la Marka, en torno a las mitades: Arajj Saya y Manqha Saya. En ella se pone en escena la adscripción y pertenencia a un grupo social específico y se recuperan las tradiciones y costumbres legadas por los antepasados. A través de la realización de los rituales, la comunidad actual se vincula con las generaciones pasadas y con los seres tutelares que custodian el orden natural y social en el que se desenvuelven mujeres y hombres en el diario vivir y quienes otorgan bienestar económico y social. Ambas mitades tienden a la endogamia y se conciben en una relación de jerarquía. Arajj Saya, concebida como masculina, posee mayor prestigio y simboliza también la costa por su posición geográfica. Mujeres y hombres pertenecientes a esta, son nominados también como Camanchacas, término que refiere a la niebla espesa proveniente de occidente. Manqha Saya posee menor prestigio y se denomina también como pampa, simbolizada en términos femeninos. Cada una de las familias posee casas en la Marka (pueblo central), la que está organizada espacialmente también en mitades. De esta manera, durante los carnavales, los grupos y comparsas se conforman por mujeres y hombres de ambas partes, los que se relacionan permanentemente mediante juegos de intercambio y competencia siempre referidos al dominio sexual (Gavilán 2001).

Uno de los días de fiesta, llamado "el día de los membrillazos", compiten ambas mitades a través del lanzamiento de esta fruta entre los hombres y hacia la campana de la torre. En este acto, puede ganar la mitad de arriba (masculino) o la mitad de abajo (femenino), pueden lograr hacer tocar la campana hembra o la campana macho. Si gana la parte femenina, se dice que va a ser un año abundante y productivo; si gana la parte masculina, habrá entonces escasez. Esta misma relación la hallamos en el sexo de los bebés. Si el primer bebé de una pareja es mujer se augura fertilidad para la nueva unidad doméstica y si nace un hombre, esta tendrá un camino difícil y tendrá que desplegar mayores esfuerzos en su trayectoria social y económica. 


\section{Lo masculino, lo femenino y las divinidades}

La dualidad masculino-femenina se manifiesta en la religiosidad a través de la presencia de parejas divinas, particularidad que se constata en la mayor parte de la literatura. El debate se sitúa en la naturaleza de estas, sus relaciones y ubicación en el cosmos. Como esperamos demostrarlo, la ambigüedad y diferencias en la interpretación entre los distintos autores radica principalmente en los significados asignados a una de las entidades presentes en gran parte de la zona andina: Pachamama, nombre otorgado por la población andina contemporánea a una de las principales divinidades.

Platt (1980) identifica a Tata Inti, Padre Sol, y Mama Killa, Madre Luna, y los ubica en la mitad superior o Pata Parti Pacha (o dimensión superior, Hanan Pacha); mientras que dentro de la tierra se ubicarían Pachatata (padre tierra) y Pachamama (madre tierra). En la mitad inferior o Ura Parti (o dimensión inferior, Ukhu Pacha). Esta última deidad recibe también el nombre de virgen, pero entre los Macha se le asignaría "mayor importancia a la fertilidad de la Madre de Dios que a su castidad" (Platt 1980:158).

Grebe (1981), a partir de su estudio en Isluga, norte de Chile, coincide con Platt (1980); sin embargo, Pachamama sería una deidad asociada a la Virgen María, por lo que su posición sería ambigua entre Arriba y Abajo, a pesar de su clara presencia en este mundo (abajo). Asociados a esta se hallarían Mallkus y T'allas, entidades que circundan en torno al espacio comunitario en la tierra. Entre estos, identifica a Torre Mallku y Santa-belin T'alla como los espíritus guardianes de la torre y de la iglesia y que mediatizan Uywir Parte (o parte de abajo) con Dios Parte; vale decir, las dos partes de la religión aymara: la cristiana y la autóctona. Postula que son concebidos como una pareja mixta antropomórfica y son recordados solamente en carnaval mediante una wilancha, ritual de sacrificio de un animal, fuera de la iglesia (Grebe 1981). Estas mismas entidades son descritas por Martínez (1990) como Santa Vitalina, Torre Mallku y Santa Plaza, tríada semejante a los santos patronos de Isluga: Concepción T'alla, Santo Tomás y Santa Bárbara.

La persistencia de las parejas sexuales en el pensamiento andino aparece repetidamente, el cual remite al hecho que las deidades siempre han de ser pareja (Madre Tierra y Cumbre), de la misma forma que los humanos.
Esta vinculación de Pachamama con los Mallkus es planteada por Harris (1980) para Bolivia. Ella propone que entre los Laymis, grupo aymara del Lago Poopó, esta es la parte femenina de los montes, encarna al espacio y el tiempo y es esposa de las cimas de las montañas. A su vez, estas últimas se relacionan a los Rayos, quienes mandan los relámpagos. De este modo, hallamos una vinculación entre Pachamama-Montañas y Rayos. Esta autora agrega componentes diabólicos a la divinidad femenina, al caracterizarla como malvada, peligrosa y voraz; por lo cual ésta dejaría de tener los contenidos virginales del catolicismo al destacar también otras dimensiones de la maternidad como el aspecto nutritivo. Ya no sería la madre trascendental sino más bien representaría el suelo fértil de cuyas cosechas viven los campesinos (Harris 1980).

Estas deidades también son descritas por Platt (1980) entre los Macha. Sugiere que Torre Mallku adquiere un significado fálico, por tanto masculino alto; mientras que la Plaza T'alla o la Iglesia representa lo femenino-bajo. Las relaciones entre estas entidades las encontramos de igual modo en los trabajos de van Kessel (1992a, 1992b). Basado en investigaciones realizadas en el norte de Chile, este autor identifica elementos culturales "autóctonos" y "externos" que se acomodarían en el panteón según el principio de tripartición. Ubica a Inti, Dios, Sol, junto a Virgen María y a los Santos en el mundo de Arriba o Arajj Pacha. Si bien la deidad femenina se halla en Arajj Pacha como lo hace Grebe (1981), ésta no es identificada a la Luna. Para este autor Pachamama se encontraría relacionada con otras dos figuras importantes: el Mallku o Espíritu de las montañas y el Amaru, la serpiente que se asocia al agua y especialmente a la limpieza y apertura de los canales de riego. Propone así que se trataría de un triple culto a la fertilidad que se centra en el agua como dadora de vida (van Kessel 1992a:211). Sugiere que a pesar del proceso de sincretismo que se ha producido entre Pachamama (llamada también Virgina) y la Virgen María serían claramente distinguibles para los aymaras. Ello se expresaría tanto en los rituales como en su designación. Mientras esta última se ubica en el cielo, la deidad andina pertenecería al Acapacha o este mundo. Sin embargo, para van Kessel existiría similitud de funciones: ser madre universal y ser virgen, a las cuales no se les reconoce esposo $^{5}$. Tienen que ver con la vida humana, pero mientras María sólo dispone indirectamente de la 
fertilidad del campo y del ganado, Pachamama es madre de toda la flora y la fauna. Su maternidad es también diferente: esta última cuida con cariño maternal la fertilidad y la salud, la alimentación de la vida y el bienestar de sus hijos en la tierra, que la respetan; María, en cambio, fue representada por los misioneros como maternidad espiritual (van Kessel 1993:36c). En este contexto, la relación entre Pachamama e Inti no es explicitada. Para este autor la deidad femenina es asexuada y no requiere de un alter masculino para la reproducción. Por otra parte, la distinción que establece van Kessel entre la deidad cristiana y andina no es tan clara para Irarrázabal (1988:31). Este habla de una extendida asociación entre la virgen cristiana y Pachamama por efecto de la evangelización católica; pero las festividades dedicadas a la virgen incorporan creencias y ritos propios del culto a la tierra o Pachamama: María habría sido pachamamaizada y Pachamama marianizada. La maternidad como componente central de Pachamama es remarcada también por algunos autores. Van Kessel sugiere que en el caso del norte de Chile los aymara se la imaginan como una mujer andina, vestida de aksu que lleva en su llijlla toda clase de cultivos y todo tipo de hierbas saludables y medicinales (van Kessel 1993:36c).

Fernández sugiere que para considerar la importancia de la Pachamama dentro de la concepción religiosa aymara es bueno tener presente el carácter insustituible de la madre dentro de una sociedad campesina que ha maternizado igualmente a la tierra. Por esta circunstancia la Pachamama si bien no tiene una imagen iconográfica unívoca está vinculada a una imagen de mujer campesina. Pachamama, madre tierra, es el paradigma pertinente en la expresión configurativa del Acapacha. Es la tierra en donde todo hombre vive, es toda la tierra, el mundo entero. Es esta tierra o este mundo con capacidad suficiente como para representar al propio Acapacha, de hecho los campesinos acostumbran a referirse a ella como pacha (Fernández 1995).

Albó (1992), por su parte, plantea que esta deidad es una y múltiples, está presente en todas partes incluso en los lugares agrestes y peligrosos y está diferenciada de una manera muy personal y particular en cada parcela concreta como Uywiri (criador), cuidador de la familia que la trabaja: puede quedar personificada además en una virgen en la capilla local. Junto a ella están todos los espíritus generadores de los diversos animales y productos. Ellos son los que al ser llamados y atendidos con cariño en los momentos cumbres del ciclo anual aseguran la fecundidad abundante de las parejas, tanto de animales como de plantas e incluso del dinero y de las personas. Estos espíritus reciben diversos nombres según el producto y los lugares germinantes de cada especie. Uno de los nombres más frecuentes es Illa o Mama Illa, referido sobre todo al espíritu multiplicador del ganado. Su nombre está relacionado con Illapa, rayo, que tiene poder duplicador de los seres y con el nombre de algunos de los nevados más majestuosos del altiplano, como el Illimani y el Illampu, fuentes de rayos y lluvias. Ispallas, Iillas y otros espíritus se concretizan además con la Pachamama, hecha imagen de la virgen, en objetos determinados como una papa de forma y tamaño excepcional, piedritas vistosas a las que se ve al caminar por las pampas e incluso amuletos elaborados artificialmente en forma de animales, de una mano que teje, de una pareja haciendo el amor, de una casa surtida con todos los bienes, etc. (Albó 1992).

Núñez del Prado, para el sur del Perú, propone que Pachamama, deidad femenina, podía en ciertas circunstancias tener una categoría similar a la deidad masculina, denominada Roal, pues sus poderes no están supeditados a los de este, ni le han sido delegados por él, como en el caso de los grandes Apus (término quechua equivalente a Mallkus). Sería más bien un ser de vigencia panterráquea que interviene como el factor femenino en la génesis. Teniendo preponderancia en la agricultura también estaría relacionada a las hembras en el génesis de los animales y vinculada a las ceremonias del Warmichakuy, matrimonio tradicional en el que tiene relación directa con la mujer y los quehaceres femeninos. En algunos casos se consideran como manifestación de la Pachamama las Wiñaque rumi (piedras emergentes), que son rocas de piedra similares a un lanzón que afloran de la tierra y se presume que provienen del centro de esta, dándosele en este caso al espíritu que las habita el tratamiento de Ñusta (Núñez del Prado 1970).

Este autor agrega otra entidad que se halla próxima a Pachamama: Pachamqaqa o simplemente Pacha. Es masculino y de naturaleza perversa, habita en los despeñaderos, barrancas y cárcavas y es él quien origina una serie de calamidades como los movimientos tectónicos. Devora también el corazón de la gente que queda dormida en los caminos, produciéndoles una enfermedad llamada pachaq hap'sisqan (cogido por Pacha). Es muy celoso de 
la integridad de la tierra y por esto en los casos en que hay que hollarla ya sea para excavación de los cimientos de una vivienda o la construcción de una acequia, es menester primero aplacar su ira ofreciéndole pagos. Pacha no tiene categoría similar a Pachamama, pues aunque maléfico no es tan poderoso como ella. Pero Pacha anda siempre con Pachamama y se dan casos en que los conceptos han sido confundidos o sincretizados, conformándose de ambas una deidad ambivalente (Núñez del Prado 1970).

A pesar de la coincidencia existente en varios autores en el aspecto de la unión del bien y el mal o lo divino y lo demoníaco, no hay acuerdos en la naturaleza de Pachamama en tanto deidad femenina y mucho menos en la relación entre esta y los cerros, nominados como Apus, Mallkus, T'allas. En esta línea, Gabriel Martínez aporta una interesante línea de interpretación. Propone la identidad del Dios del cerro con la Pachamama, es decir, del Diablo o Saxra con la Pachamama:

\section{Lo que se ha dado en llamar la Pachamama no es semióticamente otra cosa que la tematización y la figuración femenina del Diablo-Dios del cerro. O si se quiere se trata de la misma entidad masculino/feme- nino, bisexual o andrógina; qhari-warmi en quechua; mallku-t'alla, en aymara. La Pachamama actual, entendida como una deidad exclusivamente femenina, sin relación con ninguna divinidad masculi- na, diosa de la fertilidad agrícola andina, al modo de una Démeter mediterránea, madre generosa, bondadosa y protectora es un cliché, creación de diversas fuentes y extremadamente ideologizada (Martínez 1996:290).}

La figura de Dios del cerro Waka, demoníaco, dador de metales, dador de dinero, de ganado y de música ofrece una imagen cercana de lo que es la fecundidad femenina o de una "configuración uterina": metales gestándose en las entrañas de la tierra, cavidades uterinas y agujeros creacionales de donde emerge el ganado, aguas subterráneas como líquido amniótico, donde pululan pequeños ánades; imagen de la gestación femenina, pero atribuida a una divinidad que hasta el momento aparecía como definitoria de la potencia sexual masculina (Martínez 1996:290).
Esta vinculación de Pachamama con el mundo demoníaco y de los ancestros en relación a la regeneración y crecimiento es establecida también por Platt (2003), Albó (1992) y Núñez del Prado (1970). Platt, (2003) sugiere además que los aviadores, denominados como Supay por los cristianos al alma de los ancestros muertos, han contribuido a una forma peculiar de cristiandad en los Andes. Los ancestros o Chullpas y estos asociados a la influencia lunar y renaciendo en lagos en los mitos, forman parte también de la concepción de la gestación y desarrollo del nacimiento humano. El feto creciendo en el cuerpo de la mujer estaría bajo la influencia de la luna chullpa y por lo tanto el bebé debe ser preparado a través del nacimiento y bautismo para su encuentro con la luz del sol. El mito refiere a las invasiones solar del Inca y española de la sociedad lunar de los ancestros en la cual los Incas y España se unen como etapas de la nueva sociedad solar.

Bastien (1996) encuentra una variación de estos relatos en Kaata para explicar el transcurso del tiempo en el espacio. Según Bastien, los indígenas dicen que en el alba el sol se levanta desde el lago Chacamita cerca de la base oriental de la montaña de Kaata, asciende sobre las laderas inferiores durante la mañana y descansa encima de las laderas centrales en el mediodía y sube a la cima de la montaña donde muere en el lago Pachaqota, durante el crepúsculo. Pachaqota se traga el sol se hunde hasta el fondo del lago y desciende nadando por los manantiales debajo de los tres niveles hasta alcanzar el lago Cahaquamita de donde emerge el sol joven. Se utilizan analogías de la vida humana y de las plantas para explicar el diario nacimiento y muerte del sol. Aunque nacen bebés a lo largo y ancho de la montaña tienen sus orígenes como bebés miniatura cerca de la cumbre en el lago Pachaqota. Durante la vida el indígena joven camina encima de la montaña de Kaata, cruzando a menudo sus niveles mientras pastorea animales y cultiva su suelo. Cuando los indígenas se vuelven viejos mueren y son enterrados en la montaña donde ellos experimentan el ciclo regenerador. Primero se pudren hasta que sólo quedan huesos, luego nadan como una persona en miniatura hacia la cima. Los santuarios masculinos de la tierra por un lado son peñas, cerros y lugares altos; porque se cree que los hombres son permanentes como la montaña: se asientan sobre las tierras de sus antepasados masculinos. Se asocian calidades de erguimiento y permanencia con 
los hombres kaateños. Los santuarios de la tierra femeninos son los lagos y lugares bajos porque se considera que las mujeres son fértiles y cruzan los niveles (Bastien 1996).

Arnold sugiere que "aparte del énfasis nocturno, los cuentos de los orígenes agrícolas frecuentemente recalcan los temas de la sangre, el incesto y su contraparte alimentaria, o sea el canibalismo, en el contexto de la muerte y la regeneración de la vida" (Arnold y Yapita 1996:200).

La voracidad descrita para los aviadores aparece con fuerza en el período de iniciación de las actividades agrícolas o comienzo del año nuevo. Gerardo Fernández (1995) propone que el mes de agosto define el paso de la muerte a la vida. La tierra tiene hambre, sed, hambrea, está abierta y recibe con facilidad, está viva. Es también adecuado para ofrendar a los cerros sagrados. Se pide a los Achachilas o ancestros, protección y recomendación para todos los miembros de la familia y se le ofrece una mesa (ritual) a cambio de su apoyo durante el ciclo productivo (Fernández 1995).

Centrándonos ahora en los resultados obtenidos a través de nuestro trabajo de campo en la zona aymara chilena, tenemos que las interpretaciones de mujeres y hombres aymara entrevistados acerca de sus prácticas rituales, las referencias a las deidades, y a las nociones sobre la concepción y sexualidad nos permiten identificar coincidencias y divergencias con los resultados presentados anteriormente. Las deidades se ubican en dos ámbitos del cosmos. Arajj Pacha o Mundo de Arriba y AcaPacha o Este mundo ${ }^{6}$. Ambos espacios están signados por uno de los géneros: Arriba-Masculino; Abajo-Femenino, aunque ello no implica necesariamente la ausencia de parejas en el mismo nivel. En Arajj Pacha se ubica a Tata Kollanta-Dios Padre o Inti Sol y a una entidad femenina, Kollanta T'alla, aunque esta no es claramente la Luna. Se menciona a las estrellas como cohabitantes de este mundo y se denominan como hermanos/hermanas menores y mayores.

Los atributos de Inti (Dios-Sol) o Kollantata (Dios padre principal $)^{7}$ refiere a un ser masculino que cumple la función de protector de los humanos. La expresión "El nos pastea" o "El es nuestro pastorero", tan frecuentemente usada para explicar quien es Tata Kollanta, contiene la idea de cuidar con cariño, guiar por el camino correcto, velar por su vida, proteger de catástrofes y de peligros. El es padre de los seres humanos y es también el Primer Señor. Siempre tiene que ir "por delante de toda ceremonia o pedimento". El da la vida. Kollanta, en la ceremonia de la wilancha refiere específicamente al Sol del amanecer, a la primera luz de la mañana.

Pachamama $^{8}$ se representa como mujer, madre, vital ("está viva") y se ubica en Acapacha. Presenta rasgos más humanos: Tiene voluntad, ánimo, se alegra, se entristece y se enoja. Es virgen o madre de todas las plantas. Ella vive en la tierra y mantiene a la gente, la alimenta, lo cual se expresa como " $\mathrm{Da}$ bendición". Se le ama y recuerda en el tiempo de siembra y de cosecha (agosto y mayo); en los meses entre diciembre y febrero, temporada de lluvias y de fertilidad del ganado. Se podría decir que, como en el caso de Kollanta, está presente en todas las ceremonias religiosas. Se le pide permiso antes de empezar a comer o beber en la casa, en cualquier momento. Se le nombra también en las fiestas patronales. En cualquier comida festiva el primer plato que preparan las mujeres para todos los invitados se lo ofrecen a la Pachamama, ofreciéndole a la tierra en primer lugar.

Otras entidades principales destinatarias de los rituales son los Uywiris o aviadores que se ubican en el Acapacha. Estos se denominan como Mallku-T'alla, tienen nombres propios y residen en cerros, ojos de agua, piedras o montículos. Tienen sexo-género, es decir, pueden ser hombres o mujeres; residiendo solos de manera separada o ubicados ambos en un mismo lugar. Comúnmente son parejas o matrimonio y pueden tener hijos. En las ceremonias siempre son recordados en pareja, a pesar de encontrarse solos. Sus capacidades sexuales son atributos que también resaltan. En tanto "seres humanos" con capacidades sobrenaturales, dominan los espacios circundantes de la población determinando las actividades productivas, la salud y el bienestar de las personas; pueden dar vida y dar muerte. Su alimento preferido es la sangre, les gusta beber y compartir con sus devotos; resguardan el orden y la moral de los habitantes. Si no se les recuerda, castigan a través de signos como enfermedades, sequías, baja producción agrícola o ganadera. Estos castigos pueden expresarse también a través de la devoración de animales o personas, referencia que se define como hambre y/o sed de los seres tutelares.

Los términos Mallku T'alla nos remiten a una categoría de cargos de representación política y ritual de alto prestigio, asignada también a hombres y mujeres de la comunidad, cuando asumían el cargo 
social más importante. Sus características humanas refieren a un pasado indígena, específicamente a los Incas. Son también llamados Achachilas o antepasados. La representación que se hace de estos en las fiestas de los Uywiris tanto de la agricultura como de la ganadería es de una pareja de comuneros vestidos a la usanza antigua. Se visten talegas con semillas o bien piedras, con toda la indumentaria tradicional. Algunas mujeres relataron también las representaciones de mujeres en tiempo de cosecha, sin su pareja masculina. En este caso se visten costales de quinua o papa que representa la "hermana quinua" o "hermana papa", las que pueden ser denominadas como mama, mas no como T'alla. Otra característica importante de estos seres es su presencia nocturna. Normalmente son convocados a la medianoche y vistos con luna llena.

Los santos y las santas, patrones y patronas de los pueblos se aproximan a los significados otorgados a Mallku-T'alla. Ellos son celebrados en pareja para solicitar cooperación y acompañamiento en la salud y bienestar económico y social.

El análisis de los antecedentes respecto de Pachamama refiere a una entidad de un alto estatus. Aparece, como Kollanta, en todos los rituales. Sin embargo, no es invocada como los Uywiris: Mallku-T'alla. En medio de las ceremonias pueden implorar a Jutur Mallku o Jutur T'alla, Inca Mallku Inca T'alla, etc. En las oraciones nombran a Tata Dios o los Mallkus T'alla, pero no a Pachamama. Si comparamos Pachamama con los seres de los cerros, vertientes y pirkas vemos que están en directa relación. Sus atributos refieren a una entidad femenina y madre, asociada a la fertilidad: es dadora de productos agrícolas y de pastos, para los animales. Está asociada también al dinero. Ella es la tierra y está viva, son los cerros y las chacras. El lugar del rito son justamente los cerros, los pukaras (piedras arregladas como muro), donde pasta el ganado y los terrenos agrícolas. Se relaciona siempre a Kollanta Tata en las peticiones y en las fiestas patronales se le recuerda a través de la wilancha y de la acción de "ch'allar", "pautar" o "collar", términos que se refieren a brindar con bebida, hojas de coca y kopala. Su vinculación con Dios es difusa. La mayoría de las personas entrevistadas sugieren que Dios está primero y después hay que recordarse de las Pachamamas, o sea los cerros, los lugares donde comen los animales.

Estas ideas asociadas a Pachamama se acercan a las propuestas por Martínez (1996), Albó (1992) y Harris (1988). Ésta parece ser concebida como una figura femenina que contiene lo femenino y lo masculino, lo divino y lo diabólico. Refiere tanto a Mallku como a T'alla; a los santos y a las santas. En este sentido, podría ser una categoría que alude a la complementariedad de lo femenino y lo masculino como símbolo de la fertilidad y reproducción. A diferencia de lo registrado en otras comunidades andinas, en el norte de Chile no aparecen entidades masculinas conviviendo con ésta. Lo que algunos autores identifican como sus acompañantes parecen ser lo que aquí se reconoce como Mallkus, con sus nombres propios. Situación que se relaciona también con la vinculación de Pachamama con los cerros como pareja (Harris 1988). En este sentido, Pachamama podría ser la simbolización de lo masculino y femenino, en tanto que las categorías Mallku-T'alla serían los polos extremos de las nociones de sexo-género, aquella que facilita la reproducción biológica y social. La representación de Pachamama en una pareja haciendo el amor registrada por Albó (1992) en comunidades vecinas confirmaría esta línea de interpretación. Por otro lado, a pesar de que esta divinidad es mencionada y caracterizada como una entidad femenina, el hecho de que generalmente no sea nombrada en los rituales podría estar afirmando la idea de que su identidad con la Virgen María ha sido una construcción que los andinos han realizado para los no aymara, como un efecto de los procesos compulsivos de cristianización que han tenido que sobrellevar. El culto a esta entidad ambigua Pachamama-Mallku-T'alla, calificada como lo diabólico parece dirigirse, como sugiere Martínez (1996), a una suerte de configuración uterina de donde emerge la vida, pero a partir de dos materias: lo femenino y lo masculino, lo andrógino o lo bisexual.

\section{La relación de lo femenino y lo masculino como símbolos de la reproducción y fertilidad: los rituales}

Los ritos agrícolas, ganaderos y los carnavales presentan como centro de las representaciones a la fertilidad y reproducción. Estos incluyen actos simbólicos de la cópula entre ambos sexos-géneros. El momento inicial de los ritos propiciatorios, en la noche, con luna llena y referido a los Achachilas (Mallku-T'alla) representa el vínculo con el pasado. La luna, Mallkus y T'allas asociados a Pachamama 
simbolizan la fertilidad y lo femenino, como parte de la reproducción social y biológica de la comunidad. La chicha y licores (Ch'uwa), hoja de coca y kopala dispuestos en una manta especialmente tejida para estos efectos; todos productos provenientes de la tierra y que hacen posible las deidades, forman parte del gesto generoso de los comuneros para recordar y "amar" ese pasado (Gavilán 2001).

La siembra, explicada en la expresión embarazar la tierra, refiere al dominio del entendimiento sexual. Se dice "quepinchuri", que la semilla situada en un cuerpo femenino sea cubierta, guardada, protegida, así como en el seno del akso, vestido de la mujer, se cubren, guardan objetos; y "jilpan", que crezca, así como crece el sullu o feto humano. Asimismo, el feto crece igual que una planta. Así como solo en tierra fértil crecen éstas, sólo en una matriz fértil se desarrolla el feto. Lo femenino o la mujer, hace posible la vida por su capacidad de nutrir. El feto se ha producido por la mezcla de la sangre y el semen en el momento de la menstruación de la mujer.

De aquí que el período menstrual sea considerado como el momento más fértil de ésta. Es el instante en que la matriz se abre, momento único de recepción para fecundar. Pero la fertilidad máxima de la mujer será al término del sangramiento. El instante de la fecundación, momento en el que el hombre decae, podría sugerir la marcación de lo femenino, mas no la ausencia de lo masculino. Las representaciones rituales marcan a Pachamama o Mallku-T'alla, entendida como cuerpo masculino y femenino, que en el instante de la germinación, lo masculino está dormido. La manipulación ritual incluye sangre y semilla, hojas de coca, kopala, todos productos vinculados a la fertilidad. La sangre del sacrificio animal es otorgada para dar fuerza a la matriz que permitirá la germinación. Durante la ceremonia de Pukar Mallku y Pukar T'alla, ofrecida en luna nueva en la que se recuerda a los antepasados, se los invita al festejo con chicha y licores para terminar, cuando "raya el sol" con el sacrificio o wilancha de un llamo. Ello nos remite a dos momentos simbólicos de sexualidad entre lo femenino y lo masculino. La asociación de la luna nueva con el período fértil de las mujeres y con el momento en que esta tiene relaciones sexuales con el Sol o el ocaso del sol tragado por la entidad femenina del lago descrita por Bastien (1996). Dos metáforas de la unión sexual entre las divinidades. Por otra parte, Mallku-T'alla representan, en el nivel de los antepasados, entidades dadores de vida. Estos, pertenecientes al mundo de los demonios como se les caracterizó a partir de la influencia cristiana, representan el pasado abundante, a la fertilidad que requiere el presente para vivir el futuro. Así, lo que provoca la germinación o la concepción provendría desde las entrañas, de lo tectónico.

El ciclo anual del proceso agrícola para los aymara se inicia en agosto, año nuevo y período fértil de Pachamama. Esta se abre para recibir ofrendas y ofrecer fertilidad y abundancia a sus devotos. La vida comienza simbólicamente recordando a Mallkus y T'allas, reciprocando sus bondades con sangre, alimentos y chicha en un banquete compartido. El lugar de la ofrenda (el medio de la chacra, del corral, del cerro, concavidad) parece representar la matriz y las entrañas; parte central de un ser vivo o un cuerpo humano desde donde surgen la sangre y la grasa. Siguiendo a Bastien (1996) el corazón y las entrañas serían como la fuente del pensamiento y emociones, centro de la vida. El hambre y el deseo parecen confundirse. La tierra se abre: tiempo del deseo masculino y femenino (Mallku-T'alla) en la temporalidad anual, la luna nueva, tiempo del deseo femenino en la temporalidad mensual. El sol naciendo, deseo masculino en la temporalidad diaria. El ciclo menstrual, tiempo del deseo en las mujeres.

La tierra, Pachamama, simbolizada como cuerpo, algo así como una configuración uterina explicaría el lugar redundante de las ofrendas. El cuerpo sería tanto femenino como masculino. Matriz de ambos cuerpos que en el momento de la fecundación resalta la dimensión femenina, con capacidad de nutrir y contener la vida iniciada también gracias a la sustancia masculina. De aquí, el deseo sexual femenino y el masculino sería el inicio del proceso de reproducción, cuya germinación depende de la vitalidad sobrenatural promovida por las deidades.

\section{Una Aproximación a las Categorías de Diferenciación Sexual y de Género}

Una incursión en la religiosidad y en las concepciones sobre el cuerpo, el sexo y el género permite dar cuenta de las vinculaciones que la cosmovisión aymara establece en estos dominios. Lo femenino y lo masculino forman parte de un todo. Una parte aislada o abstraída, se nombra con la palabra chulla que significa algo sin su pareja, solo, sencillo, que le falta su par para ser. Esta idea se expresa en las 
ceremonias religiosas, en el discurso, en las actividades de sociabilidad, etc. (cf. Gavilán y Carrasco 2009).

En una imagen esquemática, es posible identificar algunas de las categorías pertinentes para comprender las diferencias que se establecen entre lo masculino y femenino y entre mujeres y hombres, consideradas todas como extremos polares:

\section{Categorías de las diferencias sexuales en comunidades andinas}

Del dominio religioso

\begin{tabular}{ll}
\hline \multicolumn{1}{c}{ Lo Masculino } & \multicolumn{1}{c}{ Lo Femenino } \\
\hline Arajj Pacha (mundo de arriba) & Aka Pacha (mundo de Abajo) \\
Inti & Pachamama \\
Uywir Mallku (Tata) & Uywir T'alla (Mama) \\
Jutur Mallku & Jutur T'alla \\
Pukar Mallku & Pukar T'alla \\
Santos (del santoral español) & Santas (del santoral español) \\
Torre de la Iglesia & Iglesia-Plaza \\
\hline
\end{tabular}

Concepciones de espacio-tiempo

\begin{tabular}{ll}
\hline \multicolumn{1}{c}{ Lo Masculino } & \multicolumn{1}{c}{ Lo Femenino } \\
\hline Arajj Pacha (Inti) & Aka Pacha (Pachamama) \\
Derecha & Izquierda \\
Puna & Valle \\
Costa (camanchaca) & Pampa \\
Presente & Pasado \\
Sol & Luna \\
Sol del amanecer & Luna nueva y llena \\
Día & Noche \\
Arajj Saya (mitad o & Manqha Saya (mitad o \\
comunidad de Arriba) & comunidad de Abajo) \\
\hline
\end{tabular}

Del cuerpo, sexo, sexualidad y reproducción

\begin{tabular}{ll}
\hline \multicolumn{1}{c}{ Lo Masculino } & \multicolumn{1}{c}{ Lo Femenino } \\
\hline Grasa (principio de la energía) & $\begin{array}{l}\text { Sangre menstrual (principio de } \\
\text { la vida) }\end{array}$ \\
Sangre blanca-Semen & Sangre roja coagulada \\
Espeso & Líquido \\
Duro & Blando \\
Pesado & Liviano \\
Primer orgasmo del varón define & Primer orgasmo de la mujer \\
sexo masculino & define sexo femenino \\
Formación inicial del feto: cabeza Formación inicial del feto: & manos-piernas \\
Matriz-Entrañas & Matriz-corazón \\
Protección & Nutrición \\
Útero Pequeño & Útero Grande \\
Pene que Congela-Coagula & Vagina que envuelve y ordeña \\
Contenido-Depositario & Continente, receptora \\
Capacidad sexual limitada & Capacidad sexual ilimitada \\
Movimientos fuertes y rápidos & Movimientos suaves y lentos \\
Más tiempo de gestación & Menos tiempo de gestación \\
Escasez & Abundancia \\
\hline
\end{tabular}

\section{Reflexiones Finales}

A partir de la información acopiada podemos asomarnos a una compleja representación de la relación entre sexo, sexualidad y género en las comunidades andinas. Hemos visto que para comprender los significados culturales asignados a estos conceptos es preciso conocer las representaciones de la naturaleza del cuerpo humano y de su reproducción.

De acuerdo a estos datos, los contenidos de los espacios y tiempos sagrados y profanos aymara difieren de los propiamente judeo-cristianos. Y a pesar de tratarse de una cultura subordinada respecto de la cristiana-no indígena y a la existencia de procesos históricos de cristianización y de incorporación a la sociedad nacional, existiría cierta resistencia a adoptar de una manera simple y directa los contenidos culturales externos. En este sentido, la información obtenida nos muestra la existencia de concepciones alternativas respecto de la biología del cuerpo humano y sus diferencias, las que expresan la capacidad de los aymara como agentes sociales, pues la influencia cultural y el poder de los significados de género de la sociedad colonial y republicana han estado permanentemente siendo resignificados.

En este contexto de significaciones, la sexualidad, pensada como una dimensión de los cuerpos humanos que los reproduce biológica, social y simbólicamente, no se excluye del contexto religioso sino que forma parte del sistema de creencias y cosmovisión. Habría que agregar la presencia de un tipo de sexualidad no reproductiva, como la homosexual, a pesar de su exclusión en la vida "normal" de las personas.

La forma de representar los sexos y las diferencias sexuales configuran límites imprecisos entre biología y cultura. En primer lugar deberíamos asumir que los cuerpos son diferenciados de una manera compleja. No se trata sólo de los genitales externos, ni de los aparatos reproductivos sino de su fisiología en general. Se trataría de dos cuerpos naturalmente diferentes; desde el efecto que produce el orgasmo en la definición de los sexos a su constitución ósea y orgánica que surge durante la gestación. Las representaciones de los mismos crean particularidades marcadas para cada uno de ellos en términos binarios. Cada biología y fisiología se distingue por -y se complementa con-su alter, que se precisa para la reproducción, la fertilidad, mas 
no para la sexualidad. La sexualidad entre homos es posible en el ámbito de los seres tutelares y entre estos y las personas, mas éstas "no dan frutos"; así como aquellas ocurridas entre seres de naturaleza diferente como son las personas del presente con divinidades las que arrojan seres no normales. A pesar de la clara distinción entre cuerpos femeninos y masculinos en el dominio religioso, la sexualidad no se opone del mismo modo. Los antecedentes confusos en cuanto a su orientación sexual de algunas de las deidades más importantes identificadas refieren, de algún modo, a tendencias bisexuales o a contenidos andróginos. En este sentido, es notable la ambigüedad expresada por los diferentes autores; ambigüedad expresada en su orientación sexual mas no en la naturaleza del cuerpo.

Dada la insistencia en los fluidos de los cuerpos en la reproducción, que se expresa en los rituales y en las ideas acerca de la concepción humana y agrícola, las diferencias parecen radicar en las "entrañas" y sus productos. Dinámica que hace posible, en última instancia, lo sobrenatural: las divinidades, quienes se reproducen a partir de su sexualidad ambigua. En este sentido, la categoría sexo en sí misma o podríamos decir exclusivamente, perdería relevancia para la construcción del género. Cobrarían importancia los cuerpos biológica y fisiológicamente diferentes. La no separación entre los dominios religiosos y biológicos y la forma de elaborar la relación entre cuerpos sexuados y representaciones simbólicas de los mismos nos ponen ante la cuestión de que tanto el sexo (cuerpos sexuados) como sus simbolizaciones forman parte de constructos culturales. La propuesta de Moore (1991) de que cultura y biología son conceptos histórica y culturalmente variables como las relaciones entre ellos, adquiere relevancia. Esto implicaría que dejar al sexo (cuerpos sexuados) a la biología y las representaciones culturales de los mismos al género no proporciona una solución teórica.

Las categorías hembra-macho y femeninomasculino, base del pensamiento aymara, son mediadas por la sexualidad en el contexto de la reproducción biológica y social y esta se explica por cuerpos "naturalmente" diferentes que permiten construir al género femenino y masculino a mujeres y hombres y sus relaciones. Es el ámbito de la sexualidad heterosexual. Aquí las metáforas que explican la fecundación nos hablan de sexos activos. El deseo femenino, a través de la vagina, permite la extracción del semen. Pero también el semen, en el encuentro con los fluidos femeninos, produce la gestación. Junto con esto, sería el clímax (ya sea del hombre o el de la mujer) el que incidiría en el sexo del nuevo ser.

En el espacio de la sexualidad, el hombre y la mujer, lo femenino y lo masculino no parecen estructurarse en una relación de jerarquía. Tampoco sería el caso de la reproducción o fecundación, a pesar de que el aparato reproductivo de la mujer esté marcado (recuérdese la persistencia de la configuración uterina). La reproducción biológica y social del individuo se entiende del mismo modo que la reproducción del grupo doméstico y su comunidad. Se recurre, así, a la reproducción sexual de los cuerpos diferenciados en distintos dominios de la realidad social. Significar a la organización social y espacial de la comunidad, a la cosmogonía y a los seres tutelares bajo los signos de femenino y masculino implica un recurso reiterativo de marcar las diferencias sexuales como el centro de la dinámica social.

Si seguimos a Godelier (1986), deberíamos concluir que la simbolización de los cuerpos de hombres y mujeres y de la reproducción humana entre los aymara nos indicaría que la dominación masculina se explica por el prestigio que se le otorga a estos componentes en la reproducción sexual. Pero las categorías de la diferencia sexual distan de ser simples. Las asociaciones de lo femenino y a la mujer refieren a una diversidad de elementos que a nuestros ojos parecen extraños, debido a lo que el sentido común nos indica en la cultura occidental. Por otra parte, y aun con el carácter preliminar de estas interpretaciones, deberíamos asumir que las categorías de la diferencia sexual relevan una diversidad de aspectos de los cuerpos humanos y no sólo el aparato genital. Además, el hecho de que es la sexualidad heterosexual la que produce, la que es biológicamente fértil, hace que tanto el cuerpo femenino como el masculino sean de importancia central; es decir, parecen situarse en planos diferenciados pero iguales. En este sentido, las fuentes de prestigio y poder no se situarían en este nivel. En otras palabras, la posición que ocuparía cada sexo en la reproducción, en este grupo, no explicaría las relaciones de poder existentes entre ambos. Nótese la existencia de seres tutelares femeninos "fuertes sexual y socialmente" a quienes rinden culto hasta hoy y que aparecen en los mitos y leyendas en todos los Andes. 
Podríamos concluir así que en el pensamiento aymara la unión, unidad de cuerpos distintos, gobernados simbólicamente por fuerzas divinas diferenciadas en términos de sexo-género es la clave de la vida y su reproducción. Esta unidad puede ser activada por la sexualidad de los cuerpos. No obstante, ni la sexualidad humana ni la divina están referidas solamente a lo heterosexual sino también a lo bisexual, no únicamente a las relaciones entre seres humanos sino también a las divinidades y entre estos y los anteriores. En este contexto, la sexualidad entre homos cabría dentro de las opciones posibles; a pesar de no contener la finalidad de la reproducción biológica, meta que al parecer se persigue en cada acto simbólico.

De este modo, los avances presentados nos muestran que las ideas acerca del cuerpo remiten a una esencia "biológica". Sobre la base de ésta, las ideas acerca del cuerpo, sexo y sexualidad femenina y masculina se construyen las representaciones de cada género. Podríamos proponer así la hipótesis de que así como en la población no indígena se tendió y se tiende a basar el género en representaciones de las diferencias sexuales "naturales", entre los aymara sería el carácter esencialista de las diferencias de los cuerpos de mujeres y hombres el que limita las posibilidades de transformación en las relaciones de poder entre los géneros. El hecho de afincarlo en el orden de la naturaleza, dificultaría el debate o el diálogo tanto al interior de los grupos étnicos como en su exterior, especialmente en el movimiento de mujeres. Pues, a pesar de asignar una mayor complejidad a lo femenino en la reproducción sexual y social de la comunidad, se construyen relaciones de poder a partir de la valoración dada a sus componentes en términos de prestigio, en términos de desigualdades sociales, tales como la violencia en contra de las mujeres o su exclusión de los principales medios de producción.

Pero es también el desconocimiento que tenemos de las diferencias y semejanzas de los conceptos de cuerpo, sexo, sexualidad y género entre los diferentes grupos étnicos lo que nos impide llegar a un mejor entendimiento en las luchas ya iniciadas por la igualdad social. ¿Cómo entender los procesos síquicos que ocurren en la constitución de las identidades de género en estos contextos de elaboraciones complejas del cuerpo en las que la excitación erótica o los deseos son difíciles de dilucidar? Los procesos de identidad y de construcción de subjetividades de género son variables, pero como han planteado Lamas (2002) y Moore (1994) estos parecen arraigados en la cultura y en la historia personal; no parecen ser, por tanto, tan inestables aunque se transformen en el tiempo.

Agradecimientos: Este documento ha sido preparado dentro del Proyecto FONDECYT N ${ }^{\circ}$ 1050143: "Identidades sociales en Tarapacá. Conflictos interétnicos y nacionalismos en la sociedad regional contemporánea" y del Proyecto de Investigación Mayor Ciencias y Tecnología, UTA 2008, Código 3741-08, que nos ha permitido reelaborar y analizar en profundidad antecedentes recopilados anteriormente. De igual forma, agradecemos las sugerencias aportadas por los evaluadores, que sin duda han ayudado a mejorar este artículo.

\section{Referencias Citadas}

Albó, X.

1992 La experiencia religiosa aymara. En Rostros Indios de Dios, coordinado por M. Marzal, pp. 81-130. Hisbol, La Paz.

Arnold, D.

1997 Introducción. En Más allá del Silencio. Las Fronteras de Género en los Andes, compilado por D. Arnold, pp. 13-52. Hisbol, CIASE/ILCA, La Paz.

Arnold, D. y J. Yapita, compiladores 1996 Madre Melliza y sus Crías Ispall Mama Wawampi. Antología de la Papa. HISBOL-ILCA, La Paz.

Bastien, J.

1996 La Montaña y el Cóndor. Metáfora y Ritual en un Ayllu Andino. Hisbol, La Paz.

Butler, J.

1990 Gender Trouble. Feminism and the Subversion of Identity. Routledge, New York.
Cadorette, R.

1977 Perspectivas mitológicas del mundo aymara. Allpanchis 10:115-136.

Carrasco, A.M.

1998 Constitución de género y ciclo vital entre los aymara del norte de Chile. Chungara Revista de Antropología Chilena 30:87-103.

Carrasco, A.M. y B. Cofré

2001 Antecedentes para comprender la construcción cultural de la sexualidad y la reproducción entre los aymaras contemporáneos del norte de Chile. Taller de Estudios Andinos, Serie Documentos de Trabajo, Arica.

Cereceda, V.

1978 Sémiologie des tissus andines: les talegas d'Isluga. Annales 33 (5-6):1017-1035.

Dalles, L.

1971 La miska. Allpanchis 3:28-34. 
De Barbieri, T.

1992 Sobre la categoría género. Una introducción teórico-metodológica. Isis Internacional. Ediciones de las Mujeres (Fin de Siglo. Género y cambio Civilizatorio) 17:111-128.

Fernández, G.

1995 El Banquete Aymara: Mesas y Yatiris. Hisbol, La Paz.

Gavilán, V.

2001 Los rituales propiciatorios de la vida: Un ensayo de comprensión de las formas simbólicas del género en las comunidades aymaras del norte de Chile. Taller de Estudios Andinos, Serie Documentos de Trabajo, Arica.

Gavilán, V. y A.M. Carrasco

2009 Festividades andinas y religiosidad en el norte chileno. Chungara Revista de Antropología Chilena 41:101-112.

Godelier, M.

1986 La Producción de Grandes Hombres. Poder y Dominación Masculina entre los Baruyas de Nueva Guinea. Akal, Madrid.

Grebe, M.E.

1981 Cosmovisión aymara. Revista de Santiago 1:61-79.

Harris, O.

1980 The power of signs: gender, culture and the wild in the Bolivian Andes. En Nature, Culture and Gender, editado por C. Macormarck y M. Strathern, pp. 70-94, Cambridge University Press, Cambridge.

1988 La Pachamama: significados de la madre en el discurso boliviano. En Mujeres Latinoamericanas. Diez Ensayos y una Historia Colectiva, pp. 57-75. Centro de la Mujer Peruana Flora Tristán, Lima.

INE

2003 Censo 2002. Síntesis de resultados XII Censo de población y VI de vivienda. Instituto Nacional de Estadísticas, Santiago.

Irarrázabal, D.

1988 Mutación en la identidad andina. Ritos y concepciones de la divinidad. Allpanchis 31:11-83.

Isbell, B.J.

1976 La otra mitad esencial. Un estudio de complementariedad sexual en los Andes. Estudios Andinos 12:37-56.

Lamas, $\mathrm{M}$.

2002 Cuerpo: Diferencia Sexual y Género. Editorial Taurus, México.

Martínez, G.

1990 Espacio y Pensamiento. I Andes Meridionales. Hisbol, La Paz.

1996 Saxra (diablo)/Pachamama, música, tejido, calendario e identidad entre los Jalq'a. En Cosmología y Música en los Andes, editado por M. Baumann, pp. 283-310. Iberoamericana-Vervuert, Madrid-Frankfurt.

Montes, F.

1986 La Máscara de Piedra. Simbolismo y Personalidad Aymaras en la Historia. Editorial Quipus, La Paz.

Money, J.

1986 Género: historia, teoría y uso del término en sexología y su relación con los conceptos de naturaleza y crianza. Revista Latinoamericana de Sexología 1 (2):245-261.

Moore, $\mathrm{H}$.

1991 Antropología y Feminismo. Ediciones Cátedra, Madrid.

1994 The Passion of Difference. Cambridge, London.

1999 Watever happened to woman and men? Gender and other crisis in Anthropology. En Anthropological Theory Today, editado por H. Moore, pp. 151-171. Polity Press, Cambridge.

Núñez del Prado, J.

1970 El mundo sobrenatural de los quechuas del sur del Perú, a través de la comunidad de Qotobamba. Allpanchis 2:56-119.

Ortiz, A.

1982 Moya: espacio, tiempo y sexo en un pueblo andino. Allpanchis 20:189-207.

Platt, T.

1980 Espejos y maíz. El concepto de Yanantín entre los Macha de Bolivia. En Parentesco y Matrimonio en los Andes, editado por E. Mayer y R. Bolton, pp. 139-182. Pontificia Universidad Católica del Perú, Lima.

2003 El feto agresivo. Parto, formación de la persona y mitohistoria en los Andes. Estudios Atacameños 22:127-155.

Spedding, A.

2004 Introducción a la sociología de la religión en el contexto andino. En Gracias a Dios y a los Achachilas: Ensayos de Sociología de la Religión en los Andes, editado por A. Spedding, pp. 11-71. Plural-ISEAT, La Paz.

van Kessel, J.

1992a Holocausto al Progreso. Ediciones Hisbol, La Paz. 1992b La organización tempo-espacial del trabajo entre los aymaras de Tarapacá: la perspectiva mitológica. En Etnicidad, Economía y Simbolismo en los Andes. II Congreso Internacional de Etnohistoria Corioico, compilado por S. Arze, R. Barragán, L. Escobari y X. Medinacelli, pp. 267 297. Ediciones Hisbol, La Paz.

1993 Pachamama, La Virgina: la que Creó el Mundo y Fundó el Pueblo. CIDSA, Puno.

\section{Notas}

1 Este interés surge específicamente con la realización del proyecto FONDECYT N 1990200 "Simbolizaciones de la diferencia sexual en la religiosidad de los aymara del norte chileno", de Vivian Gavilán y Ana María Carrasco. Esto porque si bien sólo en los últimos años se desarrollan de manera más sistemática estudios acerca de las ideas sobre el cuerpo, el sexo, la sexualidad y el género, el tema aparecía persistentemente en los estudios sobre religiosidad en comunidades andinas desde la década de 1970, donde los resultados de investigaciones acerca de la cosmovisión y sobre las prácticas e ideas religiosas ofrecían una variada y rica información respecto de las concepciones culturales del cuerpo, sexo y género que nos permitían reconstruir sus representaciones.

2 La información se obtuvo mediante historias de vida y entrevistas en profundidad y semi-estructuradas a una muestra intencionada de individuos. Para el caso de las entrevistas se diseñaron dos instrumentos distintos: uno para abarcar el ámbito de la sexualidad propiamente tal y otro para rescatar conocimientos sobre cuerpo y concepción. La entrevista sobre sexualidad abarcó una muestra de 40 personas, que fue seleccionada con cuatro criterios diferenciadores: sexo, 
edad, adscripción étnica y adscripción religiosa; entrevistándose a 20 hombres y 20 mujeres de tres tramos de edad y con distinta adscripción religiosa (católicos, evangélicos y sin opción). La entrevista sobre cuerpo y concepción fue aplicada a 10 individuos aymara, 5 hombres y 5 mujeres, seleccionando personas con mayor conocimiento sobre el tema (algún tipo de práctica de medicina tradicional). Finalmente, las historias de vida se aplicaron a 15 personas, aymara, hombres y mujeres de tres categorías de edad: jóvenes, adultos y adultos mayores.

3 Ambas investigadoras iniciaron su vinculación con el mundo aymara en la década de 1980, cuando crean y se integran de lleno en las actividades de promoción social e investigación, realizadas por la ONG Taller de Estudios Aymara (TEA), con sede central en la ciudad de Arica, Chile.

4 Entenderemos por sexualidad la construcción social y simbólica de la capacidad humana de derivar placer de sus cuerpos sexuados y de generar prácticas específicas de reproducción. Dicho de otro modo, la sexualidad alude a los cuerpos diferenciados en torno a su capacidad de generar deseo y placer. Por otra parte, el concepto de sexo alude a las diferencias biológicas que distinguen a hombres y a mujeres. Es también el impulso que nos lleva a buscar al otro, creándose relaciones entre ambos. Este deseo, necesidad, pulsión, es regulada a través del proceso de socialización e introyección de pautas y valores culturales, cuya vinculación con los modelos genéricos es constante y recíproca. En este sentido, el sexo no es sólo el hecho biológico de ser varón o hembra.

5 En su obra principal, este autor agrega que "no se conoce esposo ni procreador que tuviera relación con la Pachamama, y su llamada virginidad expresa explícitamente que ella genera por su propio y autosuficiente poder creador, la vida en la tierra" (van Kessel 1992a:211).

6 El mundo de adentro o Manqha pacha descrito por otros autores no apareció en ninguna de las entrevistas, lo cual puede estar en directa relación con el cómo se formularon los protocolos; pero también con el hecho de que es un ámbito sobre el cual no es fácil abordar con los no aymara. En el sector del Altiplano Sur, Jutur Mallku y Jutur T'alla es la entidad más cercana a lo demoníaco. Sin embargo, esto no es así en el sector norte, donde no adquieren mayor preponderancia. De todas maneras, es común que los Mallkus y $T$ 'allas sean nominadas como demonios, particularmente por los evangélicos.

7 En aymara también recibe los nombres de Tatita Arajj Pacha, Kollan Auquista; en español, El Señor, Tata Dios, Jesucristo, Santísimo, Santo Rey.

8 Esta deidad es llamada también Santa Tierra, Virgen Tayka, Virgen Tayka María, Mama Virgin o Santa Virgen. 